\title{
WIBRAGEC

\section{ANÁLISE DO SISTEMA DE GESTÃO DA QUALIDADE EM TRÊS EMPRESAS DA CONSTRUÇÃO CIVIL DO CEARÁ ${ }^{1}$}

\author{
SAMPAIO, Andressa Dyalla de Sá (1); ALCÂNTARA, Caio Siebra (2); CAMPOS, \\ Vanessa Ribeiro (3)
}

(1) Universidade Federal do Ceará, andressadyallasa@alu.ufc.br (2) Universidade Federal do Ceará, caiosiebra93@alu.ufc.br, (3) Universidade Federal do Ceará, vanessa.campos@ufc.br

\begin{abstract}
RESUMO
A gestão da qualidade na construção civil é primordial para as empresas que procuram diferenciais competitivos como melhorias de qualidade para atender às expectativas dos clientes. Apesar disso, a implantação de um Sistema de Gestão de Qualidade (SGQ) na construção civil possui dificuldades em assimilar as necessidades do mercado ou do cliente final. O presente trabalho tem como objetivo avaliar o SGQ de três empresas do Ceará, destacando os principais elementos formadores e suas dificuldades de manutenção. Essa análise foi feita por meio da aplicação de um questionário com 13 questões discursivas para caracterização do SGQ na estrutura das empresas da construção civil. Dessa forma, foi possível elaborar uma discussão analítica sobre a importância do Sistema de Gestão de Qualidade para as construtoras e a estrutura de implantação e manutenção do SGQ dessas empresas, destacando os elementos de inspeção, acompanhamento dos serviços e vantagens relacionadas à valorização do cliente.
\end{abstract}

Palavras-chave: Garantia de Qualidade, Controle de Qualidade, Gestão da Qualidade Total, Norma ISO 9000 .

\begin{abstract}
Quality management in civil construction is essential for companies looking for competitive advantages such as quality improvements to meet customer expectations. Despite this, the implementation of a Quality Management System (QMS) in civil construction has difficulties in assimilating it as a need of the market or of the end customer. This work aims to evaluate the QMS of three companies in Ceará, highlighting the main training elements and their maintenance difficulties. This analysis was carried out by applying a questionnaire with 13 discursive questions to characterize the QMS in the structure of civil construction companies. Thus, it was possible to prepare an analytical discussion on the importance of the Quality Management System for construction companies and a structure for the implementation and maintenance of QMS companies, highlighting the elements of execution, monitoring of services and related to customer valuation.
\end{abstract}

Keywords: Quality assurance, Quality control, Total Quality Management, ISO 9000 standard.

\section{INTRODUÇÃO}

$\mathrm{Na}$ indústria da construção civil atualmente as empresas passaram a procurar, cada vez mais, diferenciais competitivos como melhoria de qualidade, que atendam às expectativas financeiras da empresa, às exigências dos clientes e às certificações (KLEIN e CORREIO, 2019). Com isso, os efeitos da qualidade em uma empresa tornaram-se vitais para a

\footnotetext{
${ }^{1}$ SAMPAIO, A. D. de S.; ALCÂNTARA, C. S.; CAMPOS, V. R. Análise do sistema de gestão da qualidade em três empresas da construção civil do Ceará. In: SIMPÓSIO BRASILEIRO DE GESTÃO E ECONOMIA DA CONSTRUÇÃO, 12., 2021, Maceió. Anais[...] Porto Alegre: ANTAC, 2021. p.1-8. Disponível em: https://eventos.antac.org.br/index.php/sibragec/article/view/479. Acesso em: 2 out. 2021.
} 
sobrevivência e vantagem competitiva do setor de construção, como a produtividade do design e do gerenciamento de projetos (JRAISAT et al., 2016).

Com a criação de normatizações, os clientes se tornam cada vez mais exigentes e a fiscalização das normas fica mais restritiva em relação à qualidade de produtos e serviços (OLIVEIRA et al., 2011). Como exemplo de normatização na construção civil é possível citar a exigência de qualidade pela Caixa Econômica Federal para financiamento das obras. Essas exigências são baseadas na ISO 9001 e no Programa Brasileiro da Qualidade e Produtividade do Habitat - PBQP-H (KLEIN; CORREIO, 2019). Entretanto os conceitos de gestão de qualidade ainda sofrem dificuldade de aplicação nos setores da construção civil, que apesar de ter relações com a indústria manufatureira, apresentam suas especificidades (ALMADA e TONTINI, 2012).

Segundo Almada e Tontini (2012), os aspectos críticos considerados pelo cliente na construção civil são a garantia dos serviços e o acompanhamento da obra. Por outro lado, atribuições como qualidade do projeto final, assimilação de necessidades do cliente, capacidade técnica e bom relacionamento com o cliente são requisitos básicos.

Determinar os critérios de qualidade do produto é fundamental para orientar os esforços do sistema de gestão na evolução competitiva da empresa (CALARGE et al., 2015). Entretanto, obter os níveis aceitáveis de qualidade na indústria da construção há muito tempo tem sido um problema. Grandes gastos de tempo, dinheiro e recursos, tanto humanos quanto materiais, são desperdiçados a cada ano devido a procedimentos de gerenciamento de qualidade ineficientes ou inexistentes (ARDITI e GUNAYDIN, 1997).

Com isso, o presente trabalho busca analisar a implantação do Sistema de Gestão de Qualidade (SGQ) de três empresas do estado do Ceará, identificando as principais ferramentas do SGQ; critérios de monitoramento de execução, seleção de mão de obra, seleção de fornecedores de materiais, monitoramento de serviços executados por subempreiteiros e controle tecnológico dos sistemas construtivos.

O artigo foi dividido da seguinte forma, após essa seção de introdução, foi apresentado o referencial teórico, abordando um tópico sobre sistema de gestão de qualidade e outro sobre ISO 9000:2000; outra seção descrevendo a metodologia utilizada; em seguida, foi apresentada a análise dos resultados das três empresas escolhidas; e por fim, foram apresentadas as conclusões, destacando a importância do SGQ para as empresas investigadas.

\section{REVISÃO BIBLIOGRÁFICA}

Barbosa et al. (2017) afirmam que o programa de gestão da qualidade foi introduzido por Deming, Juran e Feigenbaum, que defendiam o foco no cliente, melhoria contínua, trabalho em equipe e busca constante pela atualização. Dessa forma, os criadores da gestão da qualidade focaram menos em ferramentas e técnicas e mais nos aspectos humanos da produção, uma vez que reconheceram que a simples utilização dessas ferramentas não é responsável pela gestão da qualidade.

Uma das principais tarefas de controle de qualidade é a inspeção e o gerenciamento de defeitos, com o objetivo de otimizar a satisfação do cliente final e garantir um produto de qualidade (KIM et al., 2008). Nesse contexto, existe um perigo determinante nas atividades de inspeção da construção civil que muitas vezes são sobrecarregadas pela diversidade de produtos em uma obra e colocam em risco a garantia da qualidade da construção (MA et al., 2018). Com isso, Wanberg et al. (2013) sugerem também outros indicadores de qualidade na construção civil como os custos por falhas de execução e retrabalho. 
Segundo Kim et al. (2008) os problemas de qualidade ocorrem por causa de fatores como a falta de funcionários no local para lidar com qualidade e gerenciamento de defeitos, demasiada carga de trabalho para os operários atenderem aos prazos, falta de padronização da verificação, documentos e processos e falha de comunicação entre projetistas e os gestores da qualidade.

\subsection{Sistema de Gestão de Qualidade (SGQ)}

O Sistema de Gestão da Qualidade (SGQ) é uma maneira de introduzir padronização, manutenção e melhoria da qualidade de processos, produtos e serviços (OLIVEIRA et $a l ., 2011)$. Uma das vantagens em empresas que entregam mais qualidade nos seus produtos é conseguir a fidelização dos seus clientes e consequentemente maior retorno e divulgação da empresa (ALMADA e TONTINI, 2012).

De acordo com Arditi e Gunaydin (1997), a indústria manufatureira desenvolveu conceitos de Gestão da Qualidade Total (TQM), aplicados pela primeira vez no Japão e nos últimos anos nos Estados Unidos, que aumentaram a produtividade, diminuíram o custo do produto e melhoraram sua confiabilidade. Os autores caracterizam o TQM como um esforço de melhoria do desempenho, busca por aumentar os níveis de satisfação do cliente, melhoria do envolvimento dos processos com clientes e fornecedores, cultura de inovação e avanço tecnológico, e por fim, envolvimento de toda a organização trabalhando em equipe, treinamento e educação torna a qualidade um objetivo estratégico.

Outros termos que são frequentemente utilizados de forma intercambiável são Garantia de Qualidade (GQ) e Controle de Qualidade (CQ), mas é importante manter uma clara distinção entre eles. A garantia de qualidade é toda ação planejada e sistemática necessária para proporcionar a confiança adequada de que uma estrutura, sistema ou componente terá um desempenho satisfatório e estará em conformidade com os requisitos do projeto. Por outro lado, o controle de qualidade é um conjunto de procedimentos específicos envolvidos no processo de garantia da qualidade, como planejamento, coordenação, desenvolvimento, verificação, revisão e esquematização do trabalho (ARDITI e GUNAYDIN, 1997).

\subsection{ISO 9000:2000}

O termo ISO (International Organization for Standardization) descreve a série de normas internacionais que tratam do projeto, produção, entrega, serviço e testes do produto. A série ISO 9000 compreende dois tipos básicos de normas: as que tratam da garantia da qualidade e as que tratam da gestão da qualidade (ARDITI e GUNAYDIN, 1997). Segundo Correia et al. (2006) as normas da série ISO 9000:2000 têm o intuito de considerar as expectativas das partes envolvidas no negócio (stakeholders). Dentro dessa série, a norma, que é focada em incentivar o aumento da satisfação do cliente, é a ISO 9001:2000 - Sistema de Gestão da Qualidade - Requisitos, e para o desenvolvimento do sistema de qualidade é a ISO 9004:2000 - Sistema de Gestão da Qualidade - Diretrizes para Melhoria de Desempenho. Dessa forma, a série ISO 9000:2000 torna-se um meio de desenvolvimento, medição, análise e melhoria da qualidade nas organizações (OLIVEIRA et al., 2011).

Analisando-se os parâmetros da ISO com ênfase no registro e na gestão da qualidade do processo, as normas dessa série fornecem um excelente ponto de partida para uma empresa que inicia um programa de TQM (ARDITI e GUNAYDIN, 1997). As normas ISO são direcionadas para melhorar os processos de produção de uma empresa e o TQM é o quadro geral que está preocupado com a satisfação do cliente e com todas as atividades conduzidas por uma empresa. 
Dessa maneira, a norma ISO 9000:2000 descreve oito princípios de gestão de qualidade: foco no cliente, liderança, envolvimento de pessoas, abordagem de processo, abordagem sistemática para a gestão, melhoria contínua, abordagem factual para tomada de decisão e benefícios mútuos nas relações com os fornecedores; que são usados pela alta direção para conduzir a organização à melhoria do seu desempenho. Esses oito princípios formam a base para as normas do sistema de gestão da qualidade na família NBR ISO 9000. A Figura 1 exemplifica o modelo de um sistema de gestão da qualidade, baseado no processo, descrito na norma NBR ISO 9000 (ABNT, 2000).

Figura 1 - Ilustração do processo, baseado no gerenciamento do sistema da qualidade.

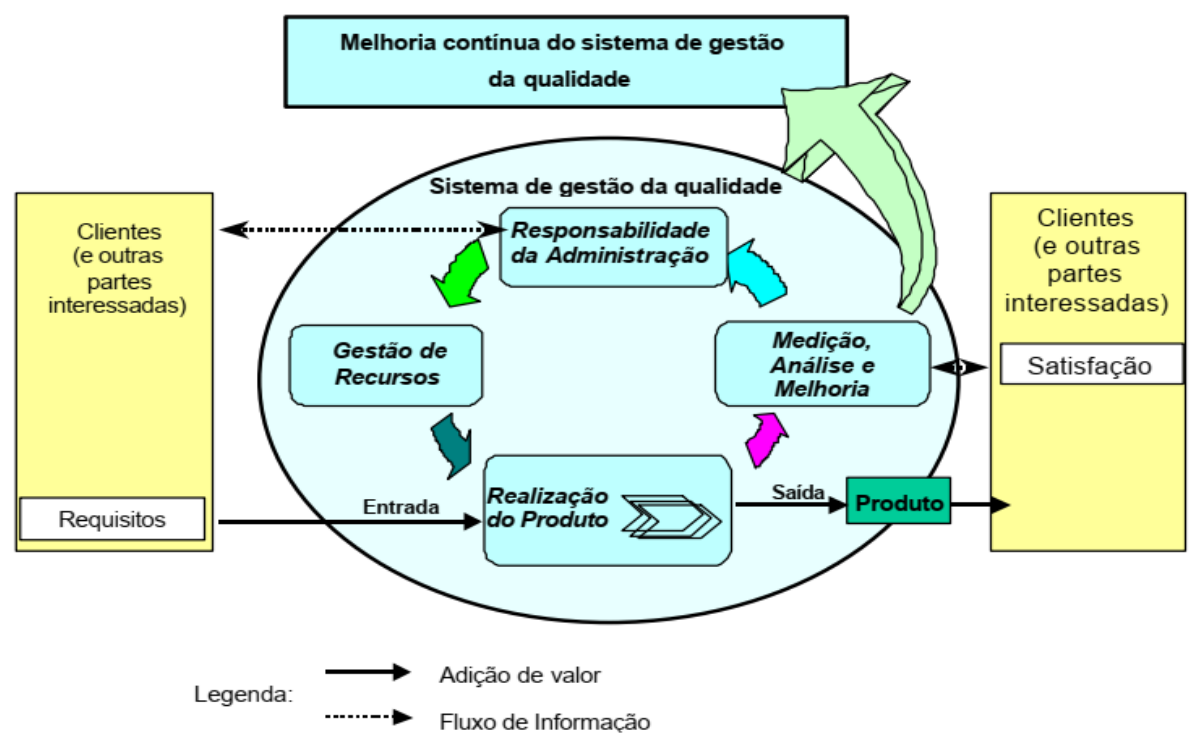

Fonte: ABNT (2000).

Segundo a norma NBR ISO 9000 (ABNT, 2000), a Figura 1 mostra que as partes interessadas desempenham um papel importante, fornecendo quatro tipos de requisitos de entrada para a organização, que são formados pela "Responsabilidade da Administração", "Gestão de recursos", "Realização do produto" e "Medição, análise e melhoria". Dessa forma, o sistema de gestão da qualidade busca a melhoria contínua do sistema, para satisfazer as necessidades dos clientes e de outras partes interessadas.

\section{METODOLOGIA}

Este trabalho consiste no estudo de caso em três empresas de construção civil no Ceará com o objetivo de analisar o sistema de gestão da qualidade. Assim, foi aplicado um questionário com 13 questões discursivas baseado na dissertação de Santana (2006), enviado para as empresas durante os meses de setembro e outubro de 2020.

De acordo com as respostas obtidas de caracterização, foi possível fazer a discussão acerca dos fatores considerados na implementação e na manutenção do SGQ pelas empresas de construção civil entrevistadas. Dessa forma, foi elaborada uma discussão analítica sobre os elementos observados em torno dos Sistemas de Gestão da Qualidade das empresas, sugerindo maior compreensão da importância da qualidade e alertando para as vantagens atreladas. O Quadro 1 apresenta as três empresas e suas características. 
Quadro 1 - Caracterização das empresas entrevistadas

\begin{tabular}{|l|l|l|l|l|l|}
\hline & $\begin{array}{l}\text { Ramo de } \\
\text { atuação/escopo }\end{array}$ & $\begin{array}{l}\text { Tempo de } \\
\text { atuação }\end{array}$ & $\begin{array}{l}\text { Porte/no de } \\
\text { funcionários }\end{array}$ & $\begin{array}{l}\text { Local de } \\
\text { atuação }\end{array}$ & SGQ \\
\hline Empresa A & Construção Civil & 21 anos & 600 & $\begin{array}{l}\text { Grande } \\
\text { Fortaleza }\end{array}$ & $\begin{array}{l}\text { ISO } \\
9001: 2015 \text { e } \\
\text { PBQP-H 2018 }\end{array}$ \\
\hline Empresa B & $\begin{array}{l}\text { Incorporação e } \\
\text { construção } \\
\text { imobiliária }\end{array}$ & 43 anos & 300 & $\begin{array}{l}\text { Grande } \\
\text { Fortaleza }\end{array}$ & $\begin{array}{l}\text { Sistema Lean } \\
\text { da Qualidade - } \\
\text { ISO 9001 }\end{array}$ \\
\hline Empresa C & Construção Civil & 7 anos & 20 & Cariri & Nenhuma \\
\hline
\end{tabular}

Fonte: Autor (2021).

A partir do Quadro 1 é possível perceber que as empresas entrevistadas apresentaram perfis diversificados. Com o número de funcionários variando de 600 a 20 e o tempo da atuação no mercado de 43 a 7 anos. Dessa forma, foi possível ter diferentes visões das empresas em relação ao SGQ.

\section{RESULTADOS E DISCUSSÕES}

As primeiras questões aplicadas foram sobre as ações praticadas pelas empresas em relação à implantação e manutenção do SGQ do sistema construtivo utilizado, mão de obra, materiais, execução e serviços terceirizados. Nesse contexto, apenas na empresa C não eram aplicadas ferramentas para o auxílio da SGQ, desenvolvendo todo o seu sistema em torno de acompanhamento técnico e inspeção. No Quadro 2 são apresentados alguns desses elementos de qualidade relatados por essas empresas.

Ao observar as informações apresentadas no Quadro 2, percebe-se que a Empresa B apresenta um acervo maior de ferramentas e técnicas de implantação e manutenção do SGQ em relação às outras empresas, pois além de ter maior experiência no mercado e maior tempo de certificação de qualidade, apresenta também técnicas com embasamento na produção enxuta, na filosofia de gestão da produção que traz redução de desperdícios e melhoria contínua para a empresa visando a satisfação do cliente.

A partir dessas práticas apresentadas pelas empresas, a inspeção, o acompanhamento e as reuniões de planejamento de curto prazo foram identificados como as ferramentas de manutenção do SGQ em comum entre as empresas. Por outro lado, treinamento e conscientização dos funcionários estão entre os elementos citados pelas empresas para vencer as barreiras que impedem o correto andamento do SGQ.

No processo de acompanhamento e manutenção do pós-obra e em relação a quais os prazos para manutenção, a Empresa A afirmou que o acompanhamento é feito pelo preenchimento do formulário de solicitação de manutenção, equipe in loco e via telefone com prazo de 5 anos. A Empresa B respondeu que possui um setor de assistência técnica responsável por acompanhar as solicitações e dar o retorno junto aos clientes sobre a procedência ou não da demanda relatada. São seguidas as recomendações normativas quanto aos prazos de garantia dos sistemas, equipamentos e materiais utilizados no empreendimento, registradas através do Manual do Proprietário e do Manual do Síndico, e são feitas análises das solicitações para classificá-las em procedente ou improcedente. $\mathrm{E}$ na Empresa $\mathrm{C}$ é feito sempre um contato direto com o cliente, buscando o mais rápido possível a resolução, caso haja qualquer problema, com prazo de 5 dias úteis. 
Quadro 2 - Práticas de SGQ apresentadas pelas empresas entrevistadas

\begin{tabular}{|c|c|c|c|}
\hline Elementos & Empresa A & Empresa B & Empresa C \\
\hline $\begin{array}{l}\text { Ferramentas do } \\
\text { SGQ aplicadas }\end{array}$ & $\begin{array}{l}\text { Espinha de } \\
\text { peixe, } 5 \mathrm{~W} 2 \mathrm{H}, \\
\text { Reuniões } \\
\text { semanais e } \\
\text { relatórios. }\end{array}$ & $\begin{array}{l}\text { Kanbans para materiais, almoxarifado } \\
\text { com uso de batalha naval para } \\
\text { localização dos produtos, controles e } \\
\text { monitoramento da obra através de } \\
\text { indicadores de longo, médio e curto } \\
\text { prazos, formulários de inspeção dos } \\
\text { serviços, registro de não conformidades } \\
\text { e ações corretivas, solução de problemas } \\
\text { e gestão do conhecimento com uso de } \\
\text { Resumo A3, gestão de riscos com } \\
\text { formulário padrão. }\end{array}$ & $\begin{array}{l}\text { Monitoramento } \\
\text { especializado por } \\
\text { profissionais } \\
\text { qualificados }\end{array}$ \\
\hline $\begin{array}{l}\text { Critérios de } \\
\text { monitoramento } \\
\text { de execução }\end{array}$ & $\begin{array}{l}\text { Indicadores de } \\
\text { Qualidade e } \\
\text { Sustentabilidade }\end{array}$ & $\begin{array}{l}\text { Auditorias periódicas nos canteiros de } \\
\text { obras e auditoria interna anual em todos } \\
\text { os processos. Além de treinamentos e } \\
\text { acompanhamento dos indicadores de } \\
\text { desempenho dos setores, das obras e dos } \\
\text { objetivos da qualidade definidos por } \\
\text { meio do planejamento estratégico da } \\
\text { empresa. }\end{array}$ & $\begin{array}{l}\text { Visita técnica de } \\
\text { eng. civil duas } \\
\text { vezes na semana, a } \\
\text { fim de prestar } \\
\text { acompanhamento } \\
\text { e orientações }\end{array}$ \\
\hline $\begin{array}{l}\text { Critérios para } \\
\text { seleção de mão } \\
\text { de obra }\end{array}$ & $\begin{array}{l}\text { Escolaridade; } \\
\text { experiência; } \\
\text { formação e } \\
\text { cursos }\end{array}$ & $\begin{array}{l}\text { Competências técnicas e } \\
\text { comportamentais, treinamentos e } \\
\text { experiências necessárias para realização } \\
\text { das atividades e uma tabela de } \\
\text { competências com base em experiência } \\
\text { e treinamentos para contratação de mão } \\
\text { de obra operacional. }\end{array}$ & $\begin{array}{l}\text { Renome de } \\
\text { mercado e } \\
\text { indicações }\end{array}$ \\
\hline $\begin{array}{l}\text { Critérios para } \\
\text { seleção de } \\
\text { fornecedores de } \\
\text { materiais }\end{array}$ & $\begin{array}{l}\text { Prazo; preço; } \\
\text { integridade e } \\
\text { qualificação }\end{array}$ & $\begin{array}{l}\text { Prazo de entrega, se são empresas } \\
\text { formais ou não, laudos e certificados } \\
\text { dos seus materiais e serviços, além de } \\
\text { especificação dos produtos conforme o } \\
\text { previsto nos projetos. }\end{array}$ & $\begin{array}{l}\text { Melhor custo- } \\
\text { benefício } \\
\text { priorizando } \\
\text { sempre a } \\
\text { qualidade } \\
\end{array}$ \\
\hline $\begin{array}{l}\text { Critérios de } \\
\text { monitoramento } \\
\text { serviços } \\
\text { executados por } \\
\text { subempreiteiros }\end{array}$ & $\begin{array}{l}\text { Inspeção do } \\
\text { serviço }\end{array}$ & $\begin{array}{l}\text { São previstas em contrato cláusulas } \\
\text { relacionadas à qualidade da execução do } \\
\text { serviço e na compra dos materiais para } \\
\text { uso nos empreendimentos, são inseridas } \\
\text { as normas técnicas aplicáveis à } \\
\text { execução dos serviços e para a liberação } \\
\text { das medições mensais, é necessário que } \\
\text { os serviços sejam concluídos e } \\
\text { validados conforme os critérios de } \\
\text { inspeção previstos na instrução lean } \\
\text { correspondente. }\end{array}$ & $\begin{array}{l}\text { Acompanhamento } \\
\text { técnico }\end{array}$ \\
\hline $\begin{array}{l}\text { Controle } \\
\text { tecnológico dos } \\
\text { sistemas } \\
\text { construtivos }\end{array}$ & $\begin{array}{l}\text { Rompimento de } \\
\text { corpo de prova } \\
24 \mathrm{~h} / 7 \mathrm{~d} / 28 \mathrm{~d} \mathrm{e} \\
\text { slump }\end{array}$ & $\begin{array}{l}\text { Ensaios para comprovação de } \\
\text { desempenho dos sistemas construtivos } \\
\text { pela NBR } 15.575, \text { como ensaios de } \\
\text { guarda-corpo, estanqueidade de } \\
\text { esquadrias, simulação de projeto e } \\
\text { ensaio in loco para análise do } \\
\text { desempenho acústico, simulação } \\
\text { computacional para análise de } \\
\text { desempenho térmico e lumínico, entre } \\
\text { outros. }\end{array}$ & Não possui \\
\hline
\end{tabular}

Fonte: Autor (2021). 
Em relação aos principais problemas relatados pelo SGQ na obra, a Empresa A respondeu que ocorrem no controle de produto e retrabalho. A Empresa B afirmou que geralmente são identificadas não conformidades na execução dos serviços (através das inspeções dos materiais), eventualmente no recebimento dos materiais (diferentes do pedido ou com algum tipo de falha no desempenho) e nos controles de indicadores e registros de inspeções. E, na Empresa $\mathrm{C}$ apontou a qualificação da mão de obra como o principal problema. Percebe-se que o principal problema encontrado nas empresas é a falta de mão de obra especializada por meio do relato das empresas de não conformidades nos serviços executados.

No último questionamento, relacionado aos benefícios alcançados com o SGQ, a Empresa A respondeu que o envolvimento das pessoas, o controle de materiais e serviços executados são os principais benefícios. Já para a Empresa B os benefícios são a padronização das atividades, a melhoria do controle na execução dos processos, a transparência na gestão dos indicadores e das atividades, a clareza nas definições de responsabilidade e autoridade na tomada das decisões e execução das tarefas, a conscientização da equipe na manutenção de registros e na gestão do conhecimento entre todas as obras, a busca constante pela perfeição através da melhoria contínua e estímulo às inovações, a maior atenção aos detalhes, a redução dos custos com manutenção pósentrega e o alto índice de satisfação dos clientes, tanto no momento da entrega da unidade quanto na pesquisa após um ano da ocupação do imóvel. Está empresa destaca também que hoje tem elevados índices de inspeção técnica das unidades privativas sem nenhuma pendência na primeira vistoria pelo cliente, o que comprova a importância de toda a cadeia de gestão da qualidade desde o desenvolvimento do projeto, passando pelo treinamento das equipes de produção, pela seleção de fornecedores de serviços e materiais, até o critério na inspeção e recebimento dos serviços. A Empresa $\mathrm{C}$ afirmou que as vantagens relacionadas ao SGQ foram qualidade na produção, baixa taxa de manutenção pós-obra, fidelização dos clientes e indicações para novos clientes.

\section{CONCLUSÃO}

Nessa pesquisa foi possível analisar o SGQ de três empresas do ramo da construção civil situadas no estado do Ceará através da aplicação de um questionário discursivo. Dessa forma, foram apresentados diferentes perfis de empresas, cada uma com um nível de implementação do SGQ.

O principal elemento de implantação e manutenção do SGQ apresentado pelas empresas foram a inspeção e acompanhamento dos serviços, corroborando o que autores como Kim et al. (2008) e Ma (2018) apresentam em seus trabalhos, mas que também alertam em relação à sobrecarga a que essas atividades estão sujeitas devido à diversidade de produtos na construção civil. Com isso, a Empresa B apresentou um maior destaque, pois além desses elementos básicos de fiscalização de qualidade, apresentou também uma filosofia lean da qualidade para melhoria dos processos e serviços.

Foi possível observar ainda a importância do SGQ para empresas construtoras, porque as três empresas se preocupam em investir em técnicas e treinamentos em mão de obra especializada, e assim aumentar a produtividade, reduzir os custos e desperdícios no processo, além de promover a satisfação do cliente, que é um dos princípios mais importantes da gestão da qualidade.

Ao analisar os três estudos de caso, percebe-se que a principal vantagem considerada pelas empresas entrevistadas é a fidelização do cliente. Esse processo está diretamente ligado ao SGQ, que tem como principal objetivo atender às necessidades ou exigências do cliente final gerando valor ao produto. 


\section{REFERÊNCIAS}

ASSOCIAÇÃO BRASILEIRA DE NORMAS TÉCNICAS. NBR ISO 9000: Sistema de Gestão da Qualidade: Fundamentos e Vocabulário. Rio de Janeiro, 2000.

ALMADA, I. W.; TONTINI, G. Atributos críticos de satisfação em serviços de arquitetura: visão do cliente x visão do arquiteto. Production, v. 22, n. 2, p. 213-224, 2012.

ARDITI, D.; GUNAYDIN, H. M. Total quality management in the construction process. International Journal of Project Management, Elsevier Science, v. 15, n. 4, p. 235-243, 1997.

BARBOSA, F. M.; GAMBI, L. N.; GEROLAMO, M.C. Liderança e gestão da qualidade - um estudo correlacional entre estilos de liderança e princípios da gestão da qualidade. Gest. Prod. [online], v. 24, n. 3, p. 438-449, 2017.

CALARGE, F. A.; FUJII, C. A. M.; SANTANA, J. C. C.; SILVA, I. L. L.; MIGUEL, P. A. C. Análise e avaliação da qualidade de serviços internos com foco na manutenção de utilidades em uma empresa de manufatura. Production, v. 26, n. 4, p. 724-741, 2015.

CORREIA, L. C. C.; MÉLO, M. A. N.; MEDEIROS, D. D. Modelo de diagnóstico e implementação de um sistema de gestão da qualidade: estudo de um caso. Production, v. 16, n. 1, p. 111-125, 2006.

JRAISAT, L.; JREISAT, L.; HATTAR, C. Quality in construction management: an exploratory study. International Journal of Quality \& Reliability Management, v. 33, n. 7, p. 920-941, 2016.

MA, Z.; CAI, S.; MAO, N.; YANG, Q.; FENG, J.; WANG, P. Construction quality management based on a collaborative system using BIM and indoor positioning.

Automation in Construction, v. 92, p. 35-45, 2018.

KIM, Y. S.; OH, Se W.; CHO, Y. K.; SEO, J. W. A PDA and wireless web-integrated system for quality inspection and defect management of apartment housing projects.

Automation in Construction, v. 17, n. 2, p. 163-179, 2008.

KLEIN, L. L.; CORREIO, M. S. T. Avaliação da gestão da qualidade em obras prediais: Contribuições práticas a partir de um estudo de caso. GEPROS - Gestão da Produção, Operações e Sistemas, v. 14, n. 4, p. 238-258, 2019.

OLIVEIRA, J. A.; NADAE, J.; OLIVEIRA, O. J.; SALGADO, M. H. Um estudo sobre a utilização de sistemas, programas e ferramentas da qualidade em empresas do interior de São Paulo. Produção, v. 21, n. 4, p. 708-723, 2011.

SANTANA, A. B. Proposta de avaliação dos sistemas de gestão da qualidade em empresas construtoras. 2006. Dissertação (Mestrado em Engenharia de Produção) Escola de Engenharia de São Carlos da Universidade de São Paulo, 2006.

WANBERG, J.; HARPER, C.; HALLOWELL, M. R.; RAJENDRAN, S. Relationship between construction safety and quality performance. Journal of Construction

Engineering and Management, v. 139, n. 10, 2013. 